\title{
Polymegathism, Pleomorphism, and Endothelial Cell Count after Selective Laser Trabeculoplasty
}

\section{N. Kurysheva*, E. Shatalova}

Ophthalmological Center of the Federal Medical and Biological Agency, Clinical Hospital No. 86, 15 Gamalei St., Moscow 123098, Russia

*Corresponding author: Kurysheva N, Diagnostic Department, Ophthalmological Center of the Federal Medical and Biological Agency, Clinical Hospital No. 86, 15 Gamalei St., Moscow 123098, Russia; E-mail: e-natalia@list.ru

Received: Jun 22, 2016; Accepted: Aug 25, 2016; Published: Oct 7, 2016

Copyright: @ 2016 Kurysheva et al. This is an open-access article distributed under the terms of the Creative Commons Attribution License, which permits unrestricted use, distribution, and reproduction in any medium, provided the original author and source are credited.

\begin{abstract}
The purpose of the study was to investigate the changes in the endothelial cell count and cell's polymegathism and pleomorphism after selective laser trabeculoplasty (SLT) in open-angle glaucoma (OAG). SLT has been performed on 18 patients (22 eyes). Each patient underwent confocal microscopy $1 \mathrm{~h}$ prior to the laser surgery and then $1 \mathrm{~h}, 1 \mathrm{day}$, 1 week, and 1 month after SLT. The obtained micrographs were then analyzed in order to study the influence of SLT on the corneal endothelium. The difference in the mean corneal endothelial cell density, polymegathism, and pleomorphism at different time intervals was found to be statistically significant. The mean endothelial cell count was reduced in 1 week after SLT from $2442 \pm 326$ per $\mathrm{mm}^{2}$ to $2352 \pm 460$ per mm $\mathrm{mm}^{2}$; polymegathism was increased from $46.1 \pm 11.7 \%$ to $50.9 \pm 13.4 \%$; and pleomorphism was decreased from $46.2 \pm 11.2 \%$ to $40.9 \pm 7.2 \%$. Cellular damage was also observed on the micrographs that were made in the follow-up after SLT. The highest quantity of damaged cells was observed $1 \mathrm{~h}$ after SLT. After 1 month, endothelial integrity was completely restored. If damaging does occur after SLT, it is not severe enough to induce serious changes in the endothelial monolayer. Nevertheless, extra care should be taken when choosing an approach to treating patients with low endothelial cell density.
\end{abstract}

Keywords: Glaucoma; Corneal endothelium; Corneal endothelial cell density; Pleomorphism; Polymegathism; Selective laser trabeculoplasty; Confocal microscopy

\section{Introduction}

Selective laser trabeculoplasty (SLT) has been used to lower IOP in the management of primary open-angle glaucoma (POAG). For several decades, since the development of argon laser trabeculoplasty by J. Wise, this procedure has been the operation of choice in the open-angle glaucoma treatment of patients in case of intolerance or ineffectiveness of drug therapy and refusal to undergo surgery.

At the beginning of the new millennium, the quantity of performed laser surgeries doubled due to the introduction of a new methodselective laser trabeculoplasty (SLT) [1]. The efficacy and safety of SLT contributed to its becoming one of the best glaucoma treatment options. The possibility of repeating the procedure facilitated an even faster spread of this method [2]. Moreover, SLT can be used as a means of reintervention after previous surgeries, including phacoemulsification and procedures in refractory glaucoma [3].

Quite soon after SLT's introduction to clinical practice, reports on possible complications, mainly inflammation, with or without visual discomfort and IOP elevation, appeared [4,5]. Permanent corneal changes after SLT are extremely rare with only two reported cases [6]. There were a few reports of post-SLT edema of the central corneal stroma, haze and subsequent corneal thinning, and scarring $[7,8]$. Much attention should be paid to the corneal endothelium.

The cornea is the frontal transparent layer of the eye that covers the pupil and iris. Its endothelium is composed of a monolayer of hexagonal cells and plays a pivotal role in the homeostasis of the cornea. These cells are characterized by polymegathism (cell size variability) and pleomorphism (cell shape variation). Even though endothelial cell count may be normal in POAG eyes, the latter may demonstrate significant morphological changes with respect to their size/area (polymegathism) and shape/hexagonality (pleomorphism). This could be the reason for postoperative keratopathy with subsequent early and rapid corneal decompensation. In our previous study we reported about early changes of the corneal endothelium cells in some patients after SLT [9]. At that time there were only few studies concerning endothelial cell count before and after SLT [10-13]. The results of these studies are controversial. In some of them scientists used specular microscopy, pleomorphism, and polymegathism of endothelium cells after SLT were not evaluated.

In the present study we have investigated the changes in the endothelial cell count and cell's polymegathism and pleomorphism after SLT in OAG.

\section{Materials and Methods}

The study has included 18 patients (22 eyes): 9 males and 9 females, aged 60 to 76 years (mean age $67.33 \pm 5.79$ ) with different stages of POAG. Sixteen eyes had pseudoexfoliation (PXF).

The study has been conducted in accordance with the principles of the Declaration of Helsinki and had the approval of the ethics committees of the hospital. We defined POAG as the presence of glaucomatous optic neuropathy (vertical cup-disc ratio $>0.7$ and/or neuroretinal rim narrowing) with associated visual field defect on automated perimetry (Swedish interactive thresholding algorithm standard 24-2 program; Humphrey field analyzer II 750i; Carl Zeiss Meditec) if the following were found: (1) glaucoma hemifield test results outside normal limits; (2) a cluster of 3 or more nonedge, contiguous points on the pattern deviation plot, not crossing the horizontal meridian with less than a $5 \%$ probability of being present in age-matched healthy individuals (one of which was $<1 \%$ ); and (3) pattern standard deviation less than 0.05 . Written informed consent was obtained from all the participants. All patients received topical hypotensive treatment, mainly prostaglandin 
Citation: Kurysheva N, Shatalova E (2016) Polymegathism, Pleomorphism and Endothelial Cell Count after Selective Laser Trabeculoplasty. Biol Med (Aligarh) 8: 343. doi:10.4172/0974-8369.1000343.

Page 2 of 5

analogues and beta-blockers. Assessments of IOP were performed at $9 \mathrm{am}, 12 \mathrm{pm}$, and $5 \mathrm{pm}$ ( 3 consecutive IOP measurements by Goldmann applanation tonometry, each was documented) and averaged to obtain the mean IOP. Central corneal thickness and corneal endothelial cell counts (ECCs) were also obtained.

Patients with corneal pathology were excluded from the study. The clinical data, including the stage of glaucoma, topical treatment prior to SLT, and laser settings, are given in Tables 1 and 2.

All the eyes requiring SLT were pretreated with brimonidine tartrate $0.15 \%$ and pilocarpine hydrochloride $2.0 \%$ prior to the procedure. The SLT procedure was performed under topical anesthesia using the Latina lens (Ocular Instruments Inc); power was initially set at $0.6 \mathrm{~mJ}$ and was increased in $0.1-\mathrm{mJ}$ steps until small bubbles appeared from the treated area of the trabecular meshwork (TM). Contiguous nonoverlapping shots were placed onto at least $180^{\circ}$ of the visible TM, avoiding areas of peripheral anterior synechiae. More nonoverlapping shots were placed when a greater extent of the trabeculum was visible. Pre-SLT IOP measurement and confocal microscopy were performed an hour prior to the surgery. The IOP was checked $60 \mathrm{~min}, 24 \mathrm{~h}, 1$ day, 1 week, and 1 month after SLT. Patients developing inflammation shortly after the surgery were prescribed instillations of indomethacin $0.1 \%$ eyedrops twice a day for 1 week after the procedure. If IOP was $28 \mathrm{~mm} \mathrm{Hg}$ or higher, the patients were prescribed timolol $0.5 \%$ twice a day. One hour after SLT, the operated eye was examined using biomicroscopy in order to reveal inflammatory response and to perform confocal microscopy. The same examination was done 1 day, 1 week, and 1 month after SLT.

\begin{tabular}{|c|c|c|c|c|}
\hline Parameter & $\begin{array}{c}\text { Minimum } \\
\text { value }\end{array}$ & $\begin{array}{c}\text { Maximum } \\
\text { Value }\end{array}$ & $\begin{array}{c}\text { Mean } \\
\text { value }\end{array}$ & $\begin{array}{c}\text { Standard } \\
\text { deviation }\end{array}$ \\
\hline Age (years) & 60.00 & 76.00 & 67.33 & 5.79 \\
\hline $\begin{array}{c}\text { Central corneal } \\
\text { thickness }(\mu \mathrm{m})\end{array}$ & 446.0 & 578.0 & 521.8 & 44.06 \\
\hline $\begin{array}{c}\text { Retinal nerve fiber layer } \\
\text { thickness }(\mu \mathrm{m})\end{array}$ & 32.35 & 106.84 & 72.64 & 27.72 \\
\hline $\begin{array}{c}\text { Perimetric index MD }(\mathrm{dB}) \\
\text { Perimetric index PSD }(\mathrm{dB})\end{array}$ & -30.76 & -1.38 & -8.45 & 8.39 \\
\hline Laser settings & & 12.52 & 4.89 & 3.85 \\
\hline Total SLT energy $(\mathrm{mJ})$ & 35.00 & 87.00 & 55.33 & 16.33 \\
\hline Degrees of SLT treatment & 180.0 & 360.0 & 250.0 & 84.84 \\
\hline IOP prior to SLT $(\mathrm{mm} \mathrm{Hg})$ & 16.00 & 39.00 & 22.75 & 8.07 \\
\hline IOP 1 h after SLT $(\mathrm{mm} \mathrm{Hg})$ & 9.00 & 25.00 & 16.89 & 5.93 \\
\hline IOP 24 h after SLT $(\mathrm{mm} \mathrm{Hg})$ & 7.00 & 20.00 & 13.83 & 4.28 \\
\hline IOP 1 week after SLT $(\mathrm{mm} \mathrm{Hg})$ & 10.00 & 30.00 & 21.30 & 6.83 \\
\hline IOP 1 month after SLT $(\mathrm{mm} \mathrm{Hg})$ & 11.00 & 20.00 & 16.6 & 3.57 \\
\hline
\end{tabular}

Table 1: Clinical data and laser settings

\begin{tabular}{|c|c|}
\hline Stage of glaucoma & Number of eyes \\
\hline Early glaucoma & 5 \\
\hline Advanced & 8 \\
\hline Far advanced & 9 \\
\hline $\begin{array}{c}\text { Topical medication (more than one type of eye drops } \\
\text { were used in some cases) }\end{array}$ \\
\hline prior to SLT \\
\hline Prostaglandin analogues & 15 \\
\hline Beta-blockers & 20 \\
\hline Carbonic anhydrase inhibitors & 3 \\
\hline
\end{tabular}

Table 2: Patient groups according to the stage of glaucoma and previous treatment
In the postoperative period, all patients were treated with a single instillation of timolol $0.25 \%$ and indomethacin $0.1 \%$.

\section{Confocal microscopy}

The mean endothelial cell density (ECD) in the central cornea, pleomorphism, and polymegathism were evaluated using micrographs taken on a confocal microscope (Confoscan 4 Nidek). The topical ocular anaesthetic was proxymetacain $0.5 \%$. The surface of the objective lens was coated with a transparent gel (Vidisic). The step distance was set to $4 \mu \mathrm{m}$, and the lamp intensity was set to $80 \%$. Only central corneal endothelium was analyzed. Of the each micrographs set, one micrograph of the best quality was selected to study ECD. These parameters were calculated automatically by means of the built-in software. The area for evaluation included at least 100 cells. In case of low-quality image series, automatic cell counting was considered unreliable, and counting was performed manually. The pleomorphism and polymegathism values were defined against normal values of $>59.0$ for pleomorphism and $<30.0 \%$ for polymegathism, which means that a normal healthy cornea should have at least $60 \%$ endothelial cells with regular shape or hexagonality and should not have abnormal endothelial cell sizes or areas (normal 312-320 micron square) in more than $30 \%$ of cells [10].

\section{Statistical analysis}

All statistical analyses were performed with the SPSS software. Mean values were tested for statistical significance with a Student's t-test.

\section{Results}

Three patients ( 3 eyes) showed moderate irritation (mixed injection) during $24 \mathrm{~h}$ after SLT. The cornea and aqueous humor of the anterior chamber were transparent (a slight endothelial bedewing was present in one eye); the iris did not show hyperemia; pupillary light response was intact; the fundus reflex was normal. An example of moderate inflammation is represented in Figure 1. Data on the postoperative IOP are given in Table 1 .

The results of confocal microscopy are given in Table 3 . The mean ECC showed a significant decrease from baseline in the SLT arm. It is of interest to note that the mean ECC showed a significant decline from the baseline in the eyes undergoing SLT, which was more pronounced in 1 week. Prior reports on the eyes with POAG suggest a transient decline in ECC following SLT, with eventual recovery at 1 month $[8,14]$, as well
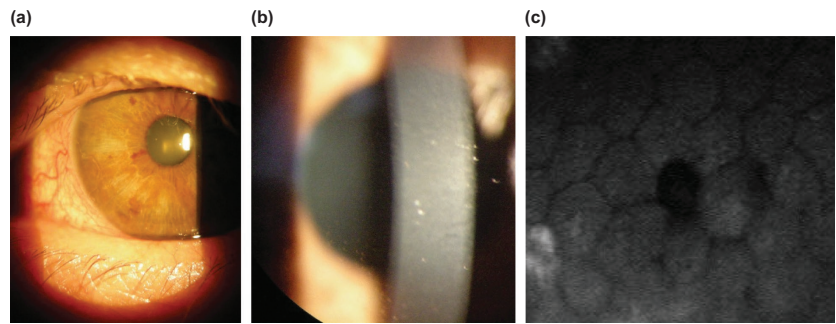

Figure 1: Biomicroscopy and confocal microscopy data, $24 \mathrm{~h}$ after SLT. a. Biomicroscopy of the anterior segment reveals moderate inflammatory response $1 \mathrm{~h}$ after SLT. b. Precipitates on the back surface of the cornea. c. Damaged endothelial cell (dark spot corresponding to the normal endothelial cell borders) 
as our study (Table 3). Polymegathism and pleomorphism were also changed significantly in 1 week, and 4 weeks posttreatment changes were not significant ( $\mathrm{t}$-test, $p=0.32$ for polymegathism and $p=0.45$ for pleomorphism).

\section{Endothelial cell morphology}

The analysis of the post-SLT micrographs revealed signs of endothelial cell damage. The endothelium was intact on all micrographs made prior to SLT. However, more than a half of the postSLT micrographs $(64.3 \%)$ made $1 \mathrm{~h}$ after the surgery showed voids equivalent to the damaged cells in the form of absolutely black spots with borders corresponding to previously existing endothelial cells (Figure 1). Thus, the voids in the endothelial monolayer were identified as dead endothelial cells. The amount of dead cells per one micrograph varied from 0 to 10 . The average number of damaged cells $1 \mathrm{~h}$ after SLT was 2.33 per micrograph. Twenty-four hours after SLT it was 1.67 cells per micrograph; 1 week and 1 month after surgery, the average number was 0.08 and 0 , respectively. The dynamics are represented in Figure 2. The examples of micrographs in dynamics are given in Figure 3 .

\section{The analysis of correlation between clinical parameters and laser settings}

In order to establish the cause of the revealed cell damage, we analyzed the correlation between the number of damaged cells in post-SLT micrographs and laser settings: energy and degree of the SLT treatment. One hour after SLT, the correlation coefficient was 0.224 $(p=0.483)$ and $0.135(p=0.675)$, respectively; $24 \mathrm{~h}$ after SLT, it was $0.027(p=0.933)$ and $0.242(p=0.449)$, respectively; 1 week after SLT, it was $0.161(p=0.618)$ and $0.260(p=0.414)$, respectively. The age of the patients or preoperative endothelial cell counts had no effect on the degree or presence of endothelial changes.

\begin{tabular}{|c|c|c|c|}
\hline & $\begin{array}{c}\text { Endothelial } \\
\text { cell count } \\
\text { (cells/mm }\end{array}$ & $\begin{array}{c}\text { Polymegathism (\%) } \\
\text { (normal }<\mathbf{3 0 . 0 \% )}\end{array}$ & $\begin{array}{c}\text { Pleomorphism (\%) } \\
\text { (normal }>\mathbf{5 9 . 0 \% )}\end{array}$ \\
\hline Prior to SLT & $2442 \pm 326$ & $46.1 \pm 11.7$ & $46.2 \pm 11.2$ \\
\hline 1 h after SLT & $2503 \pm 253$ & $50.9 \pm 9.3$ & $41.6 \pm 10.0$ \\
\hline 24 h after SLT & $2486 \pm 347$ & $51.3 \pm 9.9$ & $38.7 \pm 10.9^{*}$ \\
\hline 1 week after SLT & $2352 \pm 460^{*}$ & $50.9 \pm 13.4^{*}$ & $40.9 \pm 7.2^{*}$ \\
\hline 1 month after SLT & $2449 \pm 301$ & $41.7 \pm 5.2$ & $47.1 \pm 7.9$ \\
\hline
\end{tabular}

${ }^{*} p<0.05$ compared to the pretreatment parameter.

Table 3: Confocal microscopy data in dynamics in postoperative patients

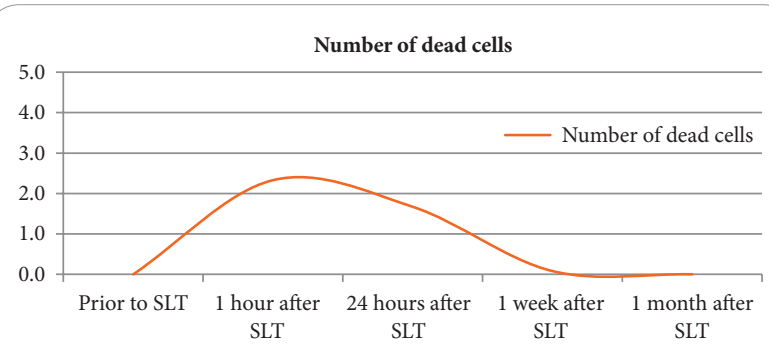

Figure 2: Dynamics of endothelial cell damage after SLT. The ordinate represents number of voids corresponding to the damaged endothelial cells per unit area of endothelium

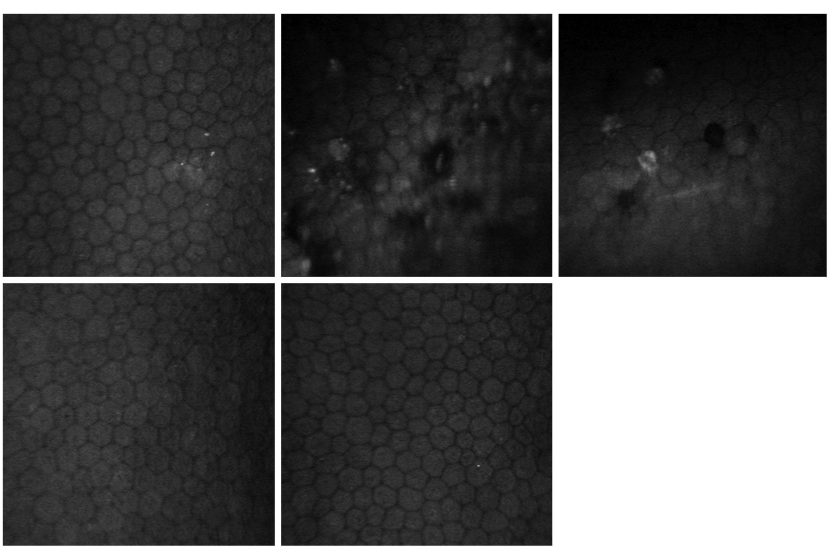

Figure 3: Micrographs of endothelium. Top row, left to right-prior to SLT, $1 \mathrm{~h}$ after SLT, and $24 \mathrm{~h}$ after SLT. Bottom row, left to right-1 week after SLT and 1 month after SLT

No significant correlation was found between the number of damaged cells after SLT and retinal nerve fiber layer thickness. The correlation coefficient was $-0.388(p=0.518) 1 \mathrm{~h}$ after SLT, -0.367 $(p=0.544) 24 \mathrm{~h}$ after SLT, and $-0.312(p=0.608) 1$ week after SLT.

Voids in post-SLT micrographs were present in half of pseudoexfoliative glaucoma patients and in all POAG patients. No connection was found between endothelial cell damage and previous topical hypotensive treatment: damaged endothelial cells were found in 5 patients previously treated with prostaglandin analogs and in 7 patients previously treated with beta-blockers. Endothelial cell damage was present in all 3 cases of registered inflammation during $24 \mathrm{~h}$ after SLT. However, it was also found in patients with no clinically significant inflammatory response.

\section{Discussion}

A possible effect of SLT on the tissues of the anterior eye segment is being discussed among researchers. The biological basis of SLT has been proposed to be a selective photothermolysis targeting the melanin in TM [14]. This sets off immune and cellular processes that modulate trabecular health and eventually result in an increased outflow through TM [15].

Some authors noted that post-SLT inflammation of the iris was greater compared to argon laser trabeculoplasty. However, it is short term, and the cytokines that are produced in inflammation facilitate the trabecular tissue remodeling, which leads to the IOP decrease [2]. For this reason, it is not recommended to prescribe corticosteroids in the postoperative period. However, there have been reports on pronounced inflammation of the anterior segment of an eye, accompanied by pain, fibrin deposition in the aqueous humor of the anterior chamber $[7,8]$, and even by choroidal effusion $[13,16]$. There was a case of spontaneous bleeding in the anterior chamber (hyphema) that occurred during SLT [9]. All mentioned complications were reversible, except for the worsening of visual function as a result of haze and scarring of central cornea reported by Meredith R. et al. [17]. The authors could not find an explanation for the complication and suggested a possible activation of herpes virus infection after SLT or immediate effect of laser energy on the cornea. It is unclear how comorbid diseases and conditions can influence ocular tissues. The endothelial monolayer is considered to 
be unaffected during SLT since laser energy is selectively absorbed by pigmented cells of TM. Other cells remain intact. Nevertheless, there are certain factors that may lead to corneal damage, namely, the use of a gonioscopy contact lens, postoperative inflammatory response, and the laser energy itself.

According to Ong K. et al., there could be no significant change, as the total corneal area through which one session of SLT treatment could maximally pass through is $6.28 \mathrm{~mm}^{2}$, which is less than $5 \%$ of the total corneal endothelial surface area [13].

However, the authors operated on the supposition that in compromised corneas and corneas with pigment deposits on endothelium there may be a risk of corneal endothelial compromise, especially after repeated SLT. The pigment may come from pigment deposition after laser peripheral iridotomy or intraocular surgery, pigment dispersion syndrome, or pigment associated with corneal guttatae. Hence, it was suggested that caution should be exercised when considering whether to repeat SLT on patients with pigment on the corneal endothelium [18].

The current study has demonstrated a reversal change in endothelial cell density, polymegathism, and pleomorphism, including in the patients with PXF. This may suggest that SLT has no negative effect on corneal endothelium. Nevertheless, post-SLT micrographs have clearly shown voids that apparently corresponded to the damaged endothelial cells

There have been reports of endothelial pathology similar to our findings. Brooks A. has noted the appearance of dark areas in the endothelial monolayer in superficial keratopathy and anterior uveitis. Moreover, the authors have demonstrated reversibility of these changes and linked dark areas to several factors: corneal edema, which elevates endothelial cells from Descemet's membrane, and deposits of inflammatory cells on the back of endothelial membrane [19].

Dark spots on specular microscopy of the corneal endothelium are sometimes present in normal corneas. They may be due to edema, subendothelial inflammatory cells, endothelial cell destruction/ dropout or inflammatory deposits and may be more numerous in some conditions such as inflammatory eye disease. Some of the dark spots may resolve when the inflammatory process resolves [19]. It should be noted, however, that dark spots seen on the micrographs obtained in the current study were more reminiscent of hexagonal "voids," exactly like normal endothelial cells. Confocal microscopy allows for more accurate differentiation between edema, cellular damage, and deposits on endothelium (unlike specular microscopy, which was used in the aforementioned study). In any case, Brooks A. noted that dark areas in the endothelial monolayer were indicative of a pathological process developing in response to inflammation.

The quantity of such cells is too low to induce serious changes in endothelial cell density, polymegathism, and pleomorphism and therefore cause detectable changes in endothelium. Nevertheless, appearance of dark spots $1 \mathrm{~h}$ after SLT in most operated patients suggests a strong connection with SLT. It can be speculated that laser energy accelerates apoptosis of endothelial cells. It remains unknown why the central corneal endothelium is involved in the apoptosis acceleration.

It has previously been suggested that inadvertent light scatter may cause corneal damage [6]. Another possibility is that the classic "champagne bubbles" released during SLT may touch the cornea as they follow convection currents in the aqueous, and this leads to focal deposits and/or cellular injury [20].

It has also been shown in rabbits that SLT can trigger a release of free radicals into the aqueous humor for a number of days after the procedure [21].

The problem of the post-SLT central corneal damage in the clinical cases described in the literature has not been solved. Perhaps further studies, involving bigger groups of patients and simultaneous study of peripheral cornea, may shed light on this issue and determine contraindications to SLT. It is important to note that patients with PXF were also enrolled in the present study. Wali U. and coauthors have revealed that corneal decompensation in PXF eyes can occur in presence of abnormalities in polymegathism and pleomorphism, even when the endothelial cell counts may be normal [10].

However, we have not revealed a significant change in endothelial cell counts, as well as in polymegathism and pleomorphism in patients with PXF compared to those with POAG. This corresponds to the findings by White and coauthors [10].

\section{Conclusion}

SLT may cause acute transient changes in the corneal endothelium. When choosing treatment options for patients with corneal pathology and/or low endothelial cell density, one should keep in mind the potential endothelial damage in SLT. It seems possible that even such minor damage as was observed in this study may facilitate endothelial dystrophy.

\section{References}

1. Realini T (2008) Selective laser trabeculoplasty, a review. J Glaucoma 17(6) 497-502.

2. Latina M, Sibayan S, Shin D (1998) Q-switched $532 \mathrm{~nm}$ Nd: YAG lase trabeculoplasty (selective laser trabeculoplasty). Ophthalmology 105(11): 2082-2090.

3. Kurysheva NI, Topolnik EV, Tsaregorodtseva MA (2008) Features of selective laser trabeculoplasty in certain types of refractory glaucoma. In: Collection of scientific papers of the international conference on glaucoma: theories, technology trends. Moscow; 2008, pp. 401-406.

4. Damji K, Shan K, Rock W (1999) Selective laser trabeculoplasty vs. argon lase trabeculoplasty: a prospective randomized clinical trial. Br J Ophthalmol 83(6): 718-722.

5. Shihaden W, Ritch R, Liebman J (2006) Hyphema occurring during selective laser trabeculoplasty. Ophthalmic Surg Lasers Imaging 37(5): 432-433.

6. Regina M, Bunya VY, Orlin SE, Ansari H (2011) Corneal edema and haze after selective laser trabeculoplasty. J Glaucoma 20(5): 327-329.

7. Moubayed S, Hamid M, Choremis J, Li G (2009) An unusual finding of corneal edema complicating selective laser trabeculoplasty. Can J Ophthalmol 44(3): 337-338.

8. Ong K, Ong L (2013) Selective laser trabeculoplasty may compromise corneas with pigment on endothelium. Clin Exp Ophthalmol 41:109-110.

9. Kurysheva N, Ryzhkov P, Topolnik E, Kapkova S (2012) Corneal endothelium after selective laser trabeculoplasty. Glaucoma 2: 36-41.

10. White AJ, Mukherjee A, Hanspal I, Sarkies NJ, Martin KR, et al. (2013) Acute transient corneal endothelial changes following selective laser trabeculoplasty. Clin Exp Ophthalmol 41(5): 435-441. doi: 10.1111/ceo.12022.

11. Lee JW, Chan JC, Chang RT, Singh K, Liu CC, et al. (2014) Corneal changes after a single session of selective laser trabeculoplasty for open-angle glaucoma. Eye (Lond) 28(1): 47-52. Epub 2013 Oct 18.

12. Ong K, Ong L, Ong L (2013) Corneal endothelial changes after selective lase trabeculoplasty. Clin Exp Ophthalmol 41(6): 537-540. doi: 10.1111/ceo.12068. Epub 2013 Mar 3 
Citation: Kurysheva N, Shatalova E (2016) Polymegathism, Pleomorphism and Endothelial Cell Count after Selective Laser Trabeculoplasty. Biol Med (Aligarh) 8: 343. doi:10.4172/0974-8369.1000343.

Page 5 of 5

13. Ramulu P, Corcoran K (2007) Utilization of various glaucoma surgeries and procedures in Medicare beneficiaries from 1995 to 2004. Ophthalmology 114(15): 2265-2270

14. Latina MA, De Leon JM (2005) Selective laser trabeculoplasty. Ophthalmol Clin North Am 18(3): 409-419.

15. Alvarado JA, Katz LJ, Trivedi S, Shifera AS (2010) Monocyte modulation of aqueous outflow and recruitment to the trabecular meshwork following selective laser trabeculoplasty. Arch Ophthalmol 128(6): 731-737.

16. Kim D, Singh A (2008) Severe iritis and choroidal effusion following selective laser trabeculoplasty. Ophthalmic Surg Lasers Imaging 39(5): 409-411.

17. Meredith R, Bunya V, Orlin S (2011) Corneal edema and haze after selective laser trabeculoplasty. J Glaucoma 20(5): 327-329.
18. Ong K , Ong L, Ong LB (2015) Corneal endothelial abnormalities after selective laser trabeculoplasty (SLT). J Glaucoma 24(4): 286-290. doi: 10.1097/ IJG.0b013e3182946381.

19. Brooks AM, Grant G, Gillies WE (1987) Reversible corneal endothelial cell changes in diseases of the anterior segment. Aust $\mathrm{N} \mathrm{Z} \mathrm{J} \mathrm{Ophthalmol} 15$ 283-289.

20. Wali UK, Al-Mujaini AS, Al-Kharusi NS, Bialasiewicz AA, Rizvi SG (2008) Quantitative and qualitative corneal endothelial morphology of omani patients with pseudoexfoliation syndrome. Sultan Qaboos Univ Med J 8(3): 300-305.

21. Guzey M, Vural H, Satici A, Karadede S, Dogan Z (2001) Increase of free oxygen radicals in aqueous humour induced by selective $\mathrm{Nd}$ : YAG lase trabeculoplasty in the rabbit. Eur J Ophthalmol 11: 47-52. 